\title{
Role of Endothelium-derived Nitric Oxide in the Bleeding Tendency of Uremia
}

\author{
Giuseppe Remuzzi, Norberto Perico, Carla Zoja, Daniela Corna, Daniela Macconi, and Gianluigi Viganò
}

Mario Negri Institute for Pharmacological Research, 24100 Bergamo, Italy

\begin{abstract}
Endothelium-derived relaxing factor, now identified as nitric oxide (NO), is a labile humoral agent formed by vascular endothelial cells from L-arginine. NO mediates the action of substances that induce endothelium-dependent relaxation and plays a role in regulating blood pressure. In this study we investigated whether NO is involved in the pathogenesis of the bleeding tendency associated with renal failure. Rats with extensive surgical ablation of renal mass develop renal insufficiency due to progressive glomerulosclerosis. Like uremic humans, rats with renal mass reduction and uremia have a bleeding tendency that manifests itself by a prolonged bleeding time. We found that $\boldsymbol{N}$-monomethyl-L-arginine (L-NMMA), a specific inhibitor of NO formation from L-arginine, completely normalized bleeding time when given to uremic rats. L-NMMA injection also increased ex vivo platelet adhesion but did not affect ex vivo platelet aggregation induced by adenosine diphosphate, arachidonic acid, and calcium ionophore A23187. The shortening effect of L-NMMA on bleeding time was completely reversed by giving the animals the NO precursor L-arginine, but not D-arginine, which is not a precursor of NO. It thus appears that NO is a mediator of the bleeding tendency of uremia. (J. Clin. Invest. 1990. 86:1768-1771.) Key words: bleeding time $\cdot$ uremic rats $\bullet$ platelet adhesion $\cdot N$-monomethyl-L-arginine $\bullet$ L-arginine
\end{abstract}

\section{Introduction}

Bleeding is a common complication of uremia (1-3). The modern management of renal failure has reduced the incidence of severe hemorrhages, but bleeding still presents a problem for uremic patients, particularly during surgery or invasive procedures. There is ample evidence that the laboratory test most greatly altered in uremia is the skin bleeding time $(2,4)$. It has been convincingly documented that the defect underlying the prolonged bleeding time of uremia involves the complex process of primary hemostasis (3), but the precise mediator(s) are still undefined.

Address correspondence and reprint requests Dr. Giuseppe Remuzzi, Mario Negri Institute for Pharmacological Research, via Gavazzeni, 11, 24100 Bergamo, Italy. 1990

Received for publication 12 June 1990 and in revised form 6 August

J. Clin. Invest.

(c) The American Society for Clinical Investigation, Inc.

$0021-9738 / 90 / 11 / 1768 / 04 \$ 2.00$

Volume 86, November 1990, 1768-1771
Endothelium-derived relaxing factor, now identified as nitric oxide (NO), ${ }^{1}$ is a labile humoral agent formed by vascular endothelial cells from $\mathrm{L}$-arginine that mediates the action of substances such as acetylcholine and bradykinin, which induce endothelium-dependent relaxation (5-8). Previous studies in laboratory animals have shown that NO plays a role in the regulation of blood pressure (9).

In view of the influence of NO on vascular tone and thrombus formation (5), we proposed to investigate whether NO mediates the defective primary hemostasis of uremia. The extreme chemical lability of NO, which has a half-life $\left(t_{-1 / 2}\right)$ of 3-5 $\mathrm{s}$ in physiological solutions (6), makes it difficult to measure NO in vivo. Thus, no data are available on whether plasma levels of NO change in various disease conditions. The possible role of NO in vivo can also be investigated using the L-arginine analogue, $N$-monomethyl-L-arginine (L-NMMA), which competitively inhibits the conversion of L-arginine to L-citrulline and NO (10-12).

In this study we investigated the effect of L-NMMA injection on the altered primary hemostasis of rats with renal mass reduction. These animals develop renal insufficiency due to a process of progressive glomerulosclerosis $(13,14)$ and, like uremic patients, have a bleeding tendency that manifests itself by a prolonged bleeding time (15).

We found that NO was involved in mediating the bleeding tendency of uremia. This may have future implications for the management of bleeding disorders.

\section{Methods}

Experimental design. Male Sprague-Dawley rats (Charles River Italia, Calco, Italy; 300 to $350 \mathrm{~g}$ ) were made uremic by surgical removal of the right kidney and ligation of two or three branches of the left renal artery according to Olson et al. (13). Renal function, measured as serum creatinine, was assayed $4 \mathrm{wk}$ after surgical procedure (15). To assess the role of NO in the bleeding tendency of uremia, we used L-NMMA, a specific inhibitor of NO formation from L-arginine. $4 \mathrm{wk}$ after the ablative procedure, eight rats received $30 \mathrm{mg} / \mathrm{kg}$ i.v. L-NMMA (Sigma Chemical Co., St. Louis, MO) in saline solution (pH 7.4) and six rats received saline as vehicle. Sham-operated rats (laparotomy and manipulation of renal pedicles but without destruction of renal tissue) receiving L-NMMA $(n=6)$ or vehicle $(n=6)$ were used as controls. Bleeding time was measured before (time 0 ) and $5,15,30$, and 60 min after injections. Systolic blood pressure was measured before and 15 min after L-NMMA or vehicle. Blood pressure was recorded in unanesthetized rats using the tail-cuff method (16).

To investigate whether the bleeding time shortening induced by L-NMMA in uremic rats was associated with changes in ex vivo platelet adhesion, 15 rats were used: sham-operated rats $(n=5)$, uremic rats

1. Abbreviations used in this paper: L-NMMA, $N$-monomethyl-L-arginine; NO, nitric oxide. 
$(n=5)$, and uremic rats $(n=5)$ given L-NMMA ( $30 \mathrm{mg} / \mathrm{kg}$ i.v.) Platelet adhesion was tested 5 min after L-NMMA injection, i.e., at the time of maximum shortening of bleeding time.

A possible effect of L-NMMA on ex vivo platelet aggregation was studied in uremic rats (two groups of six) and in sham-operated rats (two groups of six); one uremic group and one sham-operated group was given L-NMMA ( $30 \mathrm{mg} / \mathrm{kg}$ i.v.) and the others vehicle. Bleeding time, hematocrit, platelet, and leukocytes counts were measured before and $5 \mathrm{~min}$ after injections, and platelet aggregation was tested within 10 min after L-NMMA or vehicle.

To see whether the shortening of bleeding time induced by L-NMMA could be reversed by L-arginine, the precursor for NO synthesis by the vascular endothelium (8), 12 rats with renal mass reduction received $30 \mathrm{mg} / \mathrm{kg}$ i.v. L-NMMA $(n=6)$ or vehicle $(n=6)$ followed by L-arginine ( $300 \mathrm{mg} / \mathrm{kg}$ iv.; Sigma Chemical Co.) $5 \mathrm{~min}$ later. Additional rats were given D-arginine $(300 \mathrm{mg} / \mathrm{kg}$ i.v., Sigma Chemical Co.) 5 min after L-NMMA $(n=6)$ or vehicle $(n=6)$. Bleeding time was measured before and $5 \mathrm{~min}$ after L-NMMA or vehicle, and $10 \mathrm{~min}$ after L- or D-arginine.

Serum creatinine. Serum was obtained by leaving $1-\mathrm{ml}$ portions of native blood, collected from the tail vein of animals, at $37^{\circ} \mathrm{C}$ for 30 $\min$. The prepared sera were frozen and kept at $-20^{\circ} \mathrm{C}$ until assayed. Creatinine was measured by the alkaline picrate method (17).

Bleeding time. Bleeding time was measured in unanesthetized animals to avoid any possible influence of anesthesia on the blood-vessel interplay or interactions between anesthetics and drugs to be administered (15). Rats were placed in a plastic cylinder with several openings from one of which the rat's tail emerged. A standardized Simplate II device (General Diagnostics, Milan, Italy) was used, applied longitudinally on the dorsal part of the tail between 6 and $9 \mathrm{~cm}$ from the tip, taking care to avoid large veins. The tails were left in the air and the animals were kept at room temperature. Bleeding time was measured from the moment the tail was cut until bleeding stopped completely (no rebleeding within $30 \mathrm{~s}$ ). Bleeding time was expressed in seconds (normal range 80-120 s).

Ex vivo platelet adhesion. Platelet adhesion on glass beads was measured in native blood by a modification of Hellem's method (18), using standardized glass-bead-filled columns and a constant-rate $(1 \mathrm{ml}$ of blood per $15 \mathrm{~s}$ ) infusion pump (Adeplat " $\mathrm{S}$ " and Adeplat " $\mathrm{S}$ " Pump System; Mascia Brunelli, Milan, Italy).

Ex vivo platelet aggregation. Blood for platelet aggregation studies was drawn by cardiac venipuncture in $3.1 \%$ trisodium citrate $(1: 10)$. Platelet-rich plasma (PRP) was obtained by consecutive centrifugations at $200 \mathrm{~g}$ for $15 \mathrm{~min}$ then at $800 \mathrm{~g}$ for $3 \mathrm{~min}$ at room temperature; after PRP was removed and pooled the residual blood sample was centrifuged at $2000 \mathrm{~g}$ for $10 \mathrm{~min}$ to obtain platelet-poor plasma (PPP). The PRP platelet count was adjusted to $5 \times 10^{5}$ platelets $/ \mu$ l with autologous PPP. Platelet aggregation was induced by adenosine diphosphate and arachidonic acid (both from Sigma Chemical Co.), and calcium ionophore A23187 (Calbiochem-Behring Corp., La Jolla, CA) as previously described (19). Threshold-aggregating concentration was defined as the lowest concentration of aggregating agent, which induced irreversible platelet aggregation, starting within 3 min of addition of the aggregating agents to PRP.
Table I. Effect of L-NMMA or Vehicle on Bleeding Time of Sham-operated Rats

\begin{tabular}{ccl}
\hline Time & L-NMMA & Vehicle \\
\hline & $n=6$ & $n=6$ \\
Before & $100 \pm 15$ & $94 \pm 10$ \\
$5 \mathrm{~min}$ & $114 \pm 14$ & $98 \pm 14$ \\
$15 \mathrm{~min}$ & $109 \pm 19$ & $98 \pm 11$ \\
$30 \mathrm{~min}$ & $114 \pm 19$ & $97 \pm 10$ \\
$60 \mathrm{~min}$ & $112 \pm 12$ & $90 \pm 5$
\end{tabular}

Values are means \pm SD.

Statistical analysis. Data were analyzed by one- or two-way analysis of variance using Tukey's test for multiple comparisons, as appropriate (20). Results are expressed as means \pm standard deviations. Statistical significance was defined as $P<0.05$.

\section{Results and Discussion}

Animals with renal mass reduction developed renal insufficiency as documented by serum creatinine levels averaging $1.22 \pm 0.18 \mathrm{mg} / \mathrm{dl}$, while in sham-operated animals serum creatinine values were $0.56 \pm 0.08 \mathrm{mg} / \mathrm{dl}$.

Bleeding time of uremic rats was significantly $(P<0.01)$ prolonged compared with sham-operated animals (uremics [ $n$ $=12] 234 \pm 43 \mathrm{~s}$; sham $[n=12] 97 \pm 12 \mathrm{~s}$ ). The specific inhibitor of NO, L-NMMA, given intravenously to uremic rats at the dose of $30 \mathrm{mg} / \mathrm{kg}$, significantly $(P<0.01)$ shortened and actually normalized the bleeding time in all rats (Fig. 1). The effect of L-NMMA was detected within $5 \mathrm{~min}$ and lasted $15 \mathrm{~min}$. Bleeding times measured 30 and 60 min after L-NMMA injection had returned to the basal level in all animals. The vehicle alone had no effect on bleeding time in uremic rats (before: $232 \pm 55$; 5 min: $223 \pm 38$; 15 min: $243 \pm 43 ; 30$ min: $216 \pm 28 ; 60$ min: $217 \pm 29 \mathrm{~s})$. In sham-operated animals, no effect on bleeding time was detected after L-NMMA or vehicle (Table I).

L-NMMA, unlike vehicle, significantly $(P<0.01)$ increased systolic blood pressure in uremic rats (Fig. 2). L-NMMA also raised systolic blood pressure in sham-operated rats (Fig. 2), extending previous observations made in control rabbits (9).

Hematocrit, platelet, and leukocyte counts (Table II) and ex vivo platelet aggregation (Table III) were unchanged after L-NMMA or vehicle both in uremic and sham-operated rats.

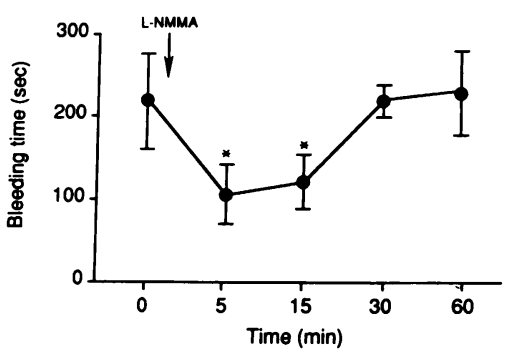

Figure 1. Effect of L-NMMA on the prolonged bleeding time of uremic rats $(n=8)$. Values are means \pm SD ${ }^{*} P<0.01$ vs. time 0 .

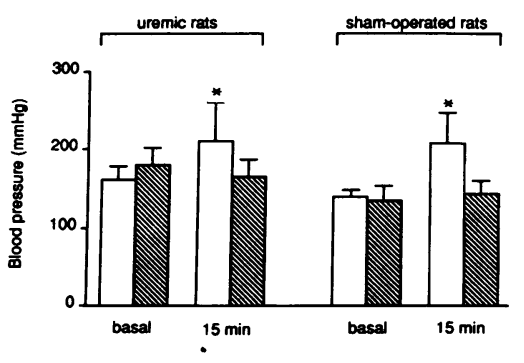

Figure 2. Effect of L-NMMA or vehicle on systolic blood pressure in uremic rats $(n=8$ and $n=6$, respectively) and sham-operated animals $(n=6$ and $n=6$, respectively). Values are means \pm SD. ${ }^{*} P<0.01$ vs. basal. $\square$, L-NMMA; $\otimes$, vehicle. 
Table II. Effect of L-NMMA or Vehicle on Bleeding Time, Hematocrit, Platelet, and Leukocyte Counts in Uremic and Sham-operated Rats

\begin{tabular}{clll}
$\frac{\text { L-NMMA }}{\text { Before } 5 \mathrm{~min}}$ & & Before $5 \mathrm{~min}$ \\
\hline$n=6$ & $n=6$
\end{tabular}

\section{Uremic rats}

$\begin{array}{lcccc}\text { Bleeding time (s) } & 238 \pm 39 & 101 \pm 8^{*} & 224 \pm 40 & 216 \pm 36 \\ \text { Hematocrit }(\%) & 45 \pm 4 & 46 \pm 6 & 43 \pm 7 & 43 \pm 6 \\ \text { Platelet count }\left(10^{4} / \mu \mathrm{l}\right) & 83 \pm 7 & 90 \pm 10 & 101 \pm 22 & 98 \pm 17 \\ \text { Leukocyte count }\left(10^{3} / \mu \mathrm{l}\right) & 18 \pm 4 & 22 \pm 8 & 16 \pm 2 & 15 \pm 4\end{array}$

Sham-operated rats

$\begin{array}{llccc}\text { Bleeding time (s) } & 86 \pm 6 & 102 \pm 8 & 101 \pm 14 & 102 \pm 12 \\ \text { Hematocrit (\%) } & 50 \pm 1 & 50 \pm 2 & 48 \pm 1 & 50 \pm 2 \\ \text { Platelet count }\left(10^{4} / \mu \mathrm{l}\right) & 92 \pm 10 & 89 \pm 15 & 92 \pm 20 & 89 \pm 11 \\ \text { Leukocyte count }\left(10^{3} / \mu \mathrm{l}\right) & 15 \pm 2 & 15 \pm 4 & 12 \pm 2 & 14 \pm 2\end{array}$

Values are means \pm SD. ${ }^{*} P<0.01$ vs. before administration.

Platelet adhesion on glass beads measured in native blood was significantly lower $(P<0.05)$ in uremic rats than in sham-operated animals (Fig. 3). In uremic rats given L-NMMA, ex vivo platelet adhesion significantly $(P<0.05)$ increased $5 \mathrm{~min}$ after the injection (Fig. 3), i.e., at the time of maximum shortening of bleeding time.

L-arginine $(300 \mathrm{mg} / \mathrm{kg}$ i.v.), but not vehicle alone, completely reversed the effect of L-NMMA on bleeding time shortening in uremic rats (Fig. 4). Similarly, L-arginine reversed L-NMMA-induced hypertension (before: $164 \pm 21$; L-NMMA: $215 \pm 20$; L-arginine: $176 \pm 25 \mathrm{mmHg}$ ). When vehicle was given instead of L-NMMA, L-arginine had no effect on systolic blood pressure (before: $177 \pm 5$; vehicle: $175 \pm 12$; L-arginine: $179 \pm 17 \mathrm{mmHg})$. D-arginine $(300 \mathrm{mg} / \mathrm{kg}$ i.v. $)$ did not affect the shortening of bleeding time (Fig. 4) or the increase in blood pressure induced by L-NMMA in uremic rats (before: $175 \pm 17$; L-NMMA: $216 \pm 13$; D-arginine: $211 \pm 16 \mathrm{mmHg}, n=6$ ).

The fact that a specific inhibitor of NO formation from L-arginine (L-NMMA) normalized the prolonged bleeding time of uremic rats and that this effect was reversed by L-arginine indicates that NO plays a major role in uremic bleeding

Table III. Arachidonic Acid (AA), Adenosine Diphosphate (ADP), and Calcium Ionophore A23187 Threshold Aggregating Concentrations of Platelet-Rich Plasma from Uremic and Sham-Operated Rats after L-NMMA or Vehicle

\begin{tabular}{lccc}
\hline & AA & ADP & A23187 \\
\hline & $m M$ & $\mu M$ & $\mu M$ \\
Uremics + L-NMMA $(n=6)$ & $0.50 \pm 0.29$ & $4.40 \pm 0.89$ & $18.0 \pm 7.65$ \\
Uremics + vehicle $(n=6)$ & $0.53 \pm 0.33$ & $4.33 \pm 0.81$ & $21.3 \pm 9.35$ \\
Sham + L-NMMA $(n=6)$ & $0.50 \pm 0.20$ & $5.50 \pm 1.00$ & $11.5 \pm 3.41$ \\
Sham + vehicle $(n=6)$ & $0.38 \pm 0.04$ & $4.40 \pm 0.89$ & $14.0 \pm 2.31$
\end{tabular}

Values are means \pm SD.

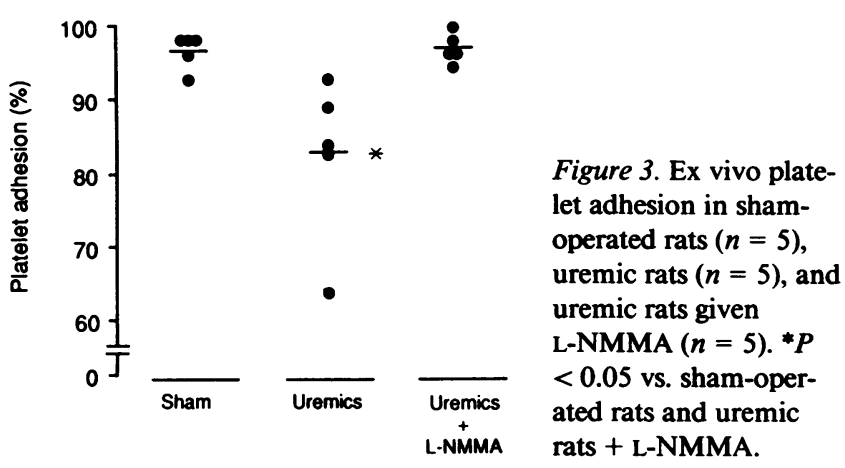

tendency. On the other hand, the observation that L-NMMA induced a further increase in systolic blood pressure in uremic rats raises the possibility that increased NO production in uremia may prevent the development of more severe hypertension.

The pathobiological significance of inhibiting NO to correct uremic bleeding can only be guessed at. Since NO is a potent vascular relaxing factor (21) it may to some extent counter the vasoconstriction that follows vessel injury. It has also been documented that NO inhibits the process of platelet adhesion to vascular endothelium by activating soluble guanylate cyclase through a heme-dependent mechanism, thereby elevating intracellular cyclic GMP (22). Data are available, however, indicating that platelet adhesion is impaired in uremia (23-25). Possibly, therefore, L-NMMA, by inhibiting the biological effect of NO, eliminates a crucial factor responsible for the impaired platelet-vessel wall adhesion in uremia. This possibility is consistent with the findings that L-NMMA given to uremic rats shortened bleeding time and increased to some extent platelet adhesion.

This is the first report of in vivo involvement of NO in the pathophysiology of a disease process. As a whole, the present findings clarify a complex issue of the uremic syndrome and may have future implications for the management of bleeding disorders with the final aim of avoiding the need for blood products and possibly reducing the risk of AIDS and other blood born diseases.
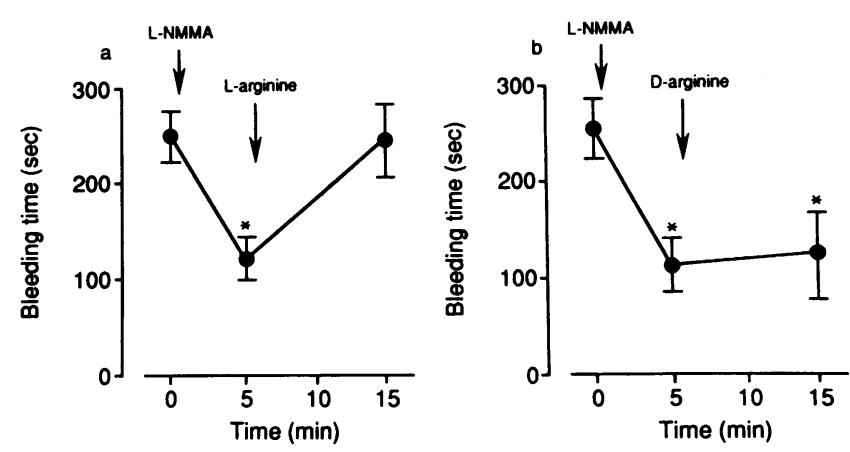

Figure 4. Effect of L-arginine $(n=6, a)$ and D-arginine $(n=6, b)$ on the shortening of bleeding time induced by L-NMMA in uremic rats. Values are means \pm SD. ${ }^{*} P<0.01$ vs. time 0 . No changes in bleeding time were observed in rats given vehicle and then injected with L-arginine $(n=6)$ or D-arginine $(n=6)$ (before: $227 \pm 33$; vehicle: 208 \pm 10 ; L-arginine: $220 \pm 21 \mathrm{~s}$; and before: $240 \pm 40$; vehicle: $270 \pm 16$; D-arginine: $247 \pm 21 \mathrm{~s})$. 


\section{Acknowledgments}

This work was partially supported by grants from the National Institutes of Health, contracts HL-41136 and HL-37491.

\section{References}

1. Lewis, J. H., M. B. Zucker, and J. H. Ferguson. 1956. Bleeding tendency in uremia. Blood. 11:1073-1076.

2. Deykin, D. 1983. Uremic bleeding. Kidney Int. 24:698-705.

3. Remuzzi, G. 1988. Bleeding in renal failure. Lancet. $i: 1205-$ 1208.

4. Steiner, R. W., C. Coggins, and A. C. A. Carvalho. 1979. Bleeding time in uremia: a useful test to assess clinical bleeding. Am. J. Hematol. 7:107-117.

5. Moncada, S., R. M. J. Palmer, and E. A. Higgs. 1987. Prostacyclin and endothelium-derived relaxing factor: biological interactions and significance. In Thrombosis and Haemostasis. M. Verstraete, J. Vermylen, R. Lijnen, and J. Arnout, editors. Leuven University Press, Leuven, Belgium. 597-618.

6. Ignarro, L. J. 1989. Endothelium-derived nitric oxide: actions and properties. FASEB (Fed. Am. Soc. Exp. Biol.) J. 3:31-36.

7. Vanhoutte, P. M., and H. Shimokawa. 1989. Endothelium-derived relaxing factor and coronary vasospasm. Circulation. 80:1-9.

8. Palmer, R. M. J., D. S. Ashton, and S. Moncada. 1988. Vascular endothelial cells synthesize nitric oxide from L-arginine. Nature (Lond.). 333:664-667.

9. Rees, D. D., R. M. J. Palmer, and S. Moncada. 1989. Role of endothelium-derived nitric oxide in the regulation of blood pressure. Proc. Natl. Acad. Sci. USA. 86:3375-3378.

10. Rees, D. D., R. M. J. Palmer, H. F. Hodson, and S. Moncada. 1989. A specific inhibitor of nitric oxide formation from L-Arginine attenuates endothelium-dependent relaxation. Br. J. Pharmacol. 96:418-424.

11. Palmer, R. M. J., D. D. Rees, D. S. Ashton, and S. Moncada 1988. L-Arginine is the physiological precursor for the formation of nitric oxide in endothelium-dependent relaxation. Biochem. Biophys. Res. Commun. 153:1251-1256.

12. Palmer, R. M. J., and S. Moncada. 1989. A novel citrullineforming enzyme implicated in the formation of nitric oxide by vascular endothelial cells. Biochem. Biophys. Res. Commun. 158:348-352.

13. Olson, J. L., T. H. Hostetter, H. G. Rennke, B. M. Brenner, and
M. A. Venkatachalam. 1982. Altered glomerular permselectivity and progressive sclerosis following extreme ablation of renal mass. Kidney Int. 22:112-126.

14. Hostetter, T. H., J. L. Olson, H. G. Rennke, M. A. Venkatachalam, and B. M. Brenner. 1981. Hyperfiltration in remnant nephrons: a potentially adverse response to renal ablation. Am. J. Physiol. 241:F85-F93.

15. Zoja, C., G. Viganò, A. Bergamelli, A. Benigni, G. de Gaetano, and G. Remuzzi. 1988. Prolonged bleeding time and increased vascular prostacyclin in rats with chronic renal failure: effects of conjugated estrogens. J. Lab. Clin. Med. 112:380-386.

16. Pfeffer, J. M., M. A. Pfeffer, and E. D. Frohlic. 1971. Validity of an indirect tail-cuff method for determining systolic arterial pressure in unanesthetized normotensive and spontaneously hypertensive rats. $J$. Lab. Clin. Med. 78:957-962.

17. Bonsnes, R. W., H. H. Taussky. 1945. The colorimetric determination of creatinine by the Jaffe reaction. J. Biol. Chem. 158:581586.

18. Hellem, A. J. 1970. Platelet adhesiveness in von Willebrand's disease. Scand. J. Haematol. 7:374-382.

19. Zoja, C., N. Perico, A. Bergamelli, M. Pasini, M. Morigi, J. Dadan, A. Belloni, T. Bertani, and G. Remuzzi. 1990. Ticlopidine prevents renal disease progression in rats with reduced renal mass. Kidney Int. 37:934-942.

20. Linton, M., and P. S. Gallo. 1975. The Practical Statistician: Simplified Handbook of Statistics. Brooks/Cole Publishing Company, Monterey, CA.

21. Palmer, R. M. J., A. G. Ferrige, and S. Moncada. 1987. Nitric oxide release accounts for the biological activity of endothelium-derived relaxing factor. Nature (Lond.). 327:524-526.

22. Radomski, M. W., R. M. J. Palmer, and S. Moncada. 1987. The role of nitric oxide and CGMP in platelet adhesion to vascular endothelium. Biochem. Biophys. Res. Commun. 148:1482-1489.

23. Salzman, E. W., and L. L. Neri. 1966. Adhesiveness of blood platelets in uremia. Thromb. Diath. Haemorrh. 15:84-92.

24. Remuzzi, G., M. Livio, G. Marchiaro, G. Mecca, and G. de Gaetano. 1978. Bleeding in renal failure: altered platelet function in chronic uraemia only partially corrected by haemodialysis. Nephron. 22:347-353.

25. Evans, E. P., R. A. Branch, and A. L. Bloom. 1987. A clinical and experimental study on platelet function in chronic renal failure. $J$. Clin. Pathol. (Lond.). 25:745-753. 